\title{
Present Status of Eri-Muga Culture in Ne Region and Related Biodiversity Resources as Tool for Sustainable Economic Uplifting of Seri-Stakeholders
}

\author{
Meghasree Baishya ${ }^{1 *}$, Himangshu Barman², Sheikh Abdus Safur Rahman ${ }^{3}$ \\ ${ }^{1}$ Project Assistant, Central Silk Board, Regional Sericulture Research Station, India \\ ${ }^{2}$ Scientist C, Central Silk Board, Regional Sericulture Research Station, India \\ ${ }^{3}$ Scientist D, Central Silk Board, Regional Sericulture Research Station, India
}

*Address for Correspondence: Meghasree Baishya, Project Assistant, DST (SEED), Regional Sericulture Research Station, Central Silk Board, Boko, Kamrup, Assam, India

E-mail: meghasree.baishyasbi@gmail.com

Received: 16 Oct 2018/ Revised: 22 Jan 2019/ Accepted: 28 Apr 2019

\begin{abstract}
Beyond history reach, silkworm culture has been invariably occupying as economic tool parallel to human civilization in the world's nukes and corners. "Kalika-Puran" depict vanya fabrics-Muga and Eri as "Kasuga" that was in abundant use in the Kamrup. Some other reliable historical document that reveals uses of Muga and Eri silk in Kamrupa are Kalhan's Raj Taranginii, Kautilya's Arthasastra, and Harshacharit. The famous Chinese traveller 'Huen Tsang' wrote a note on use and trade of Muga and Eri silk in Kamrupa kingdom. At the present era, there is a gap between actual production and potential production. However, Eri production in India a steady growth from $2760 \mathrm{mt}$ during 2010 - 2011 to $5060 \mathrm{mt}$ in 2015 - 2016 has accounted for compounded annual growth of $12.89 \%$. In the case of Muga silk although several constraints have been prominently affecting during the last 6years, recorded a compounded growth of $6.01 \%$. In 2010 - 2011 only $124 \mathrm{mt}$ was produced which reach the production line of $166 \mathrm{mt}$ in 2015 - 2016. Several interacting factors directly-indirectly are catalyzing production. Most prominent is a collaborative effort of Central Silk Board and respective states Sericulture Department implementing several farmers beneficial scheme supporting their sericulture growth. The intervention of fashion technologies and diversification of products catalyses domestic and global market demand growth of silk products. Technology intervention at different stakes has been found working. The exploitation of Seri-biodiversity resources may be instrumental in production growth. It will open a new dimension "Do Sericulture with Agriculture".
\end{abstract}

Key-words: Kasaga, Kalika-Puran, Muga, Serigenus, Seri-biodiversity, Seri-stakeholder

\section{INTRODUCTION}

Available ancient historical records of Indian subcontinent mention sericulture along with Agricultural practices was a mean of livelihood of humankind. Existence of silk Route also reveals Silk Economy among South-East Asian kingdoms covering Indian subcontinent including then Kamrupa. An illustrious example was "Kalika-Puran ${ }^{[1]}$ where depicted the use of cloths by

\section{How to cite this article}

Baishya M, Barman H, Rahman SAS. Present Status of Eri-Muga Culture in Ne Region and Related Biodiversity Resources as Tool for Sustainable Economic Uplifting of Seri-Stakeholders. SSR Inst. Int. J. Life Sci., 2019; 5(3): 2284-2290.

\begin{tabular}{|c|c|}
\hline & Access this article online \\
\hline
\end{tabular}

inhabitants of Kamrupa as four types- Karpasa (Cotton), Kambala (Wool), Balka (Bark) and Kasaga (Silk). In Kautillya's Arthasastra ${ }^{[2]}$. It has been mentioned that Kamrupa kingdom is called as the kingdom of cocoon rearer. Kalhan's Raj Taranginii ${ }^{[3]}$ depicts that princess Amritprabha married prince of Kashmir and brought with her the famous 'Chatri' of Kamrupa made up of muga silk along with others rapped with decorative Muga silk fabrics. The famous chinese buddhist traveller 'HuenTsang' ${ }^{[4]}$ wrote a note on use and tread of silk like Muga and Eri in Kamrupa kingdom. Another famous historical book Banabhatta's "Harshasharit" [5] also mention the use of Muga silk in then Bhaskar Barman's Kamrupa. But, the present scenario of silk economy is 
quite different as advancement of sciences and Being a traditional practice, sericulture particularly Eri and Muga silkworm in NE region has been involving the indigenous people particularly various tribal communities. The women folks of various tribal communities as well as economically backward families of other communities have been practicing Muga and Eri culture. The climate as well as soil conditions of NE region of India are so suitable for abundant flourish of various serigenus insects ${ }^{[6-9]}$ including domesticated Antheraea assamensis and Samia ricini. Variations in soil types also concerted with luxury of different Muga and Eri silkworm food plants ${ }^{[10]}$. A sizable variety of primary food plants of Eri silkworm, e.g. castor exist in this region besides having several other secondary food plants. Although, improvement through breeding has been achieved in castor plant for more yield of seed, but for better yield of leaf there has been less effort in breeding of this Eri food plant so far. Similarly in the case of Muga silkworm food plant, several species are abundant both in wild and cultivated conditions. Several morpho-types plants are prevailing in wild vegetation as well as cultivated, no genetically improved breed or hybrid comes in to Muga culture practices ${ }^{[11,12]}$. Further, in the field of disease management of Eri and Muga silkworms only preventive measures have been practicing by the rears that to the available methods developed for Mulberry Silkworm. Stable curative methods of various diseases of these economically important silkworms are still at stray. Thus, farmers have been culturing these silkworms with mostly age old traditional methods; however some short of technological interventions may technologies are concern.

be accounted. Being sericulture national issue, both central and state government have been giving more emphasis to boost this industry as being one of important factor for rural employment and national economic growth ${ }^{[13]}$. As such, several vital schemes had so far implemented catalysing enhance silk production in the country. In Eri sector there has been a satisfactory compounded growth of $12.89 \%$ since $2010-2011$ to 2015-2016 ${ }^{[14]}$. Contrary to Eri Silk production, Muga Silk production was far behind achieving only $6.01 \%$ compound growth during 2010 - 2011 to 2015 - $2016^{\text {[14] }}$.

Production Scenario of Eri-Muga silk- Although there was less technological intervention in the cocoon production of Eri, national production growth has been a little bit satisfactory. Of the total silk production in India, Eri silk contributes $17 \%$ and about $90 \%$ of national Eri silk production is attributed by North Eastern States. Most of Eri farmers do this culture in traditional manner, but due to relentless effort and money investment in different schemes, national production of Eri has showed an increasing growth during the period from 2010-2011 to 2015-2016 accounting a compounded growth of $12.89 \%$ [15]. At other stakes of this culture, technological interventions are prominent. Product diversification also helps in economic uplifting of stakeholders. After all this depends upon the raw Eri cocoon production. There are enormous scopes to increase raw Eri silk to several folds then present through technology intervention in this sector. National production growth of Eri silk has been represented diagrammatically by Fig. 1 \& Fig. 2.

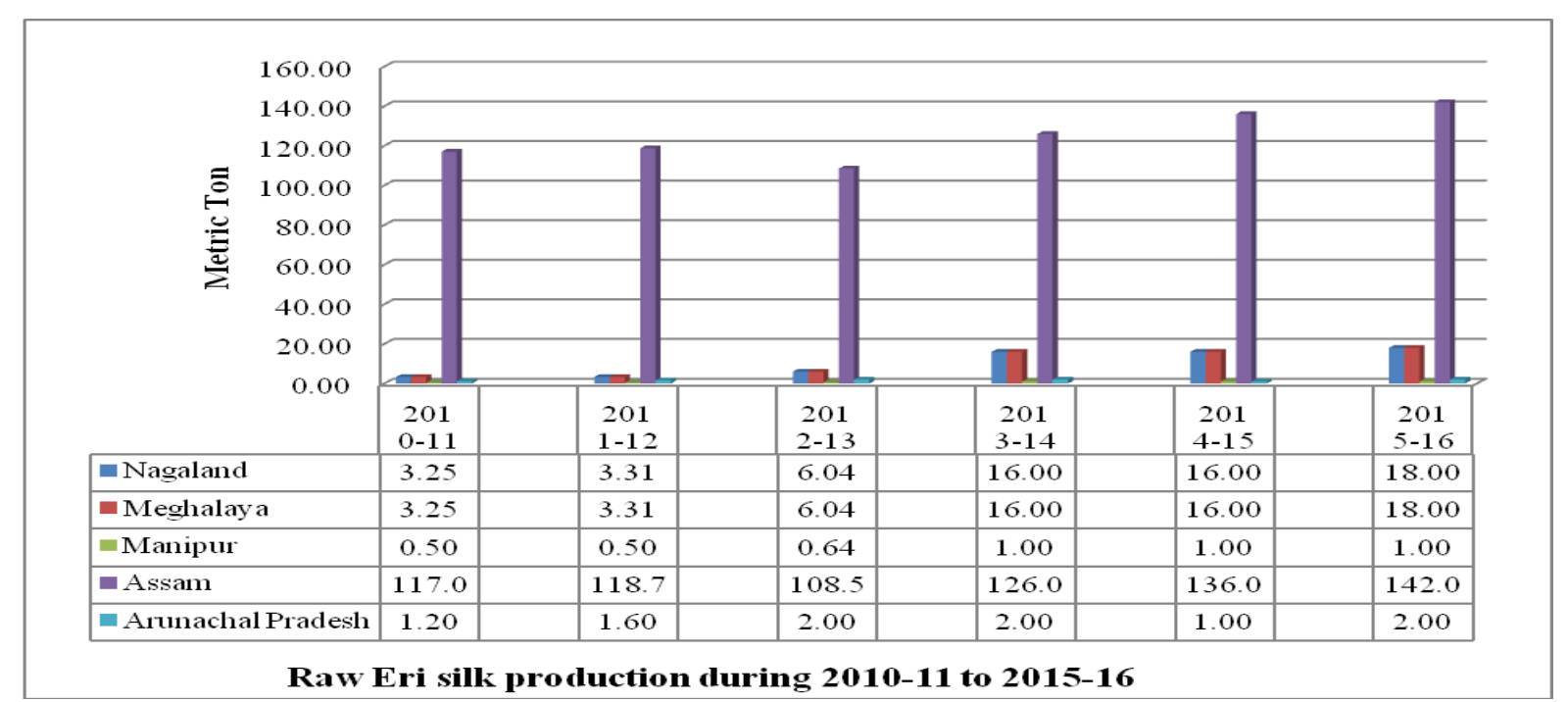

Fig. 1: Raw Eri silk production in 5 NE states of India during the period 2010-2011 to 2015-2016 (Source- M/O Statistics \& Programme Implementation) 


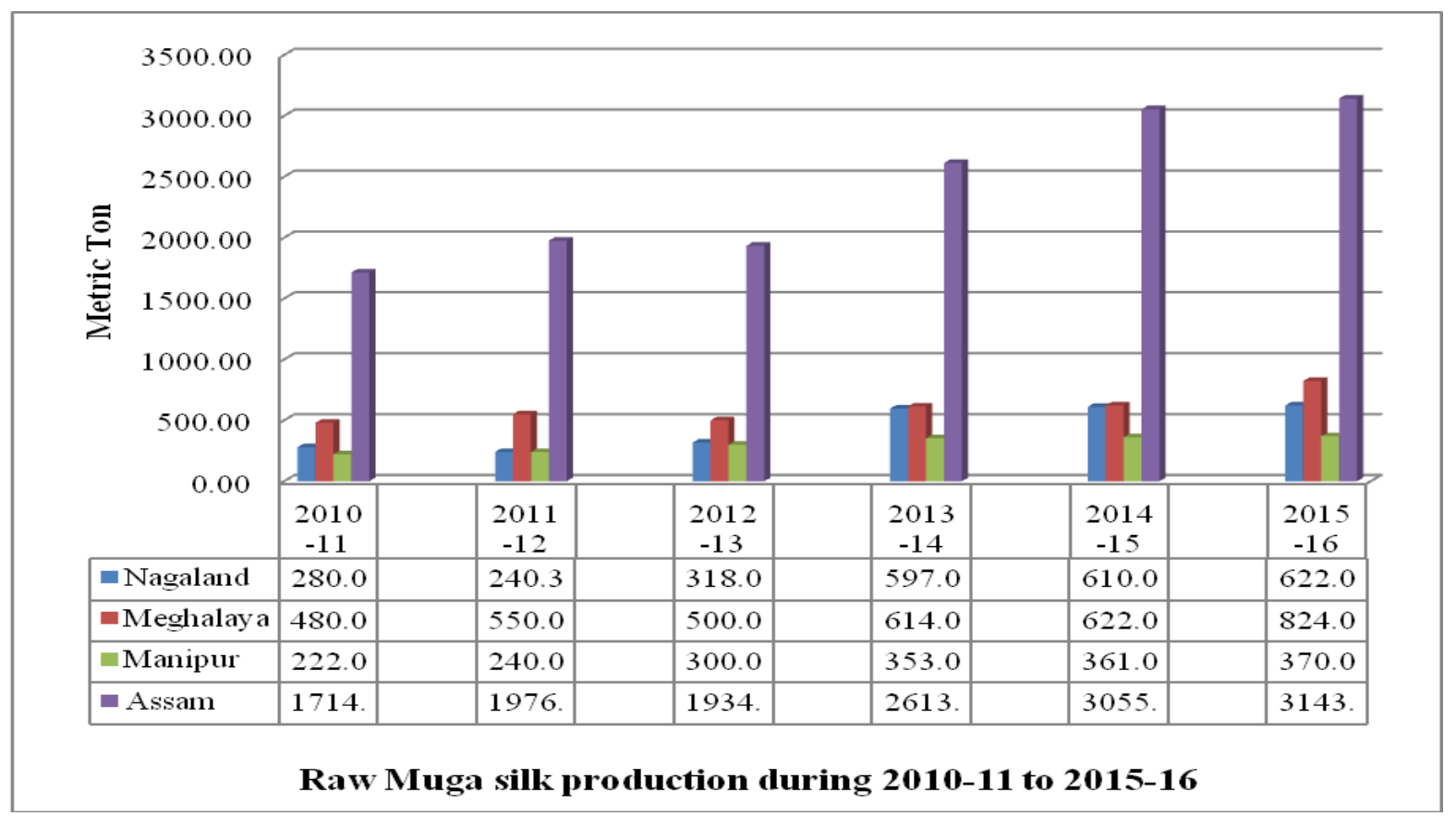

Fig. 2: Raw Muga silk productions in 4 NE states of India during the period 2010-2011 to 2015 - 2016 (Source- M/O Statistics \& Programme Implementation)

Unlike Eri silk production, Muga silk production growth was very slow accounting a compounded growth of 6.01\% during 2010-2011 to 2015-2016 [14]. Although technology interventions are there at cocoon production and Muga seed production stakes, this sector has been encountering constrains in different ways. As production is not satisfactory, technology intervention fails to encourage the Muga Farmers. In other post cocoon stakes, there are full technology interventions and stakeholders have been benefited. National production growth of Raw silk has been represented diagrammatically by Fig. 3.

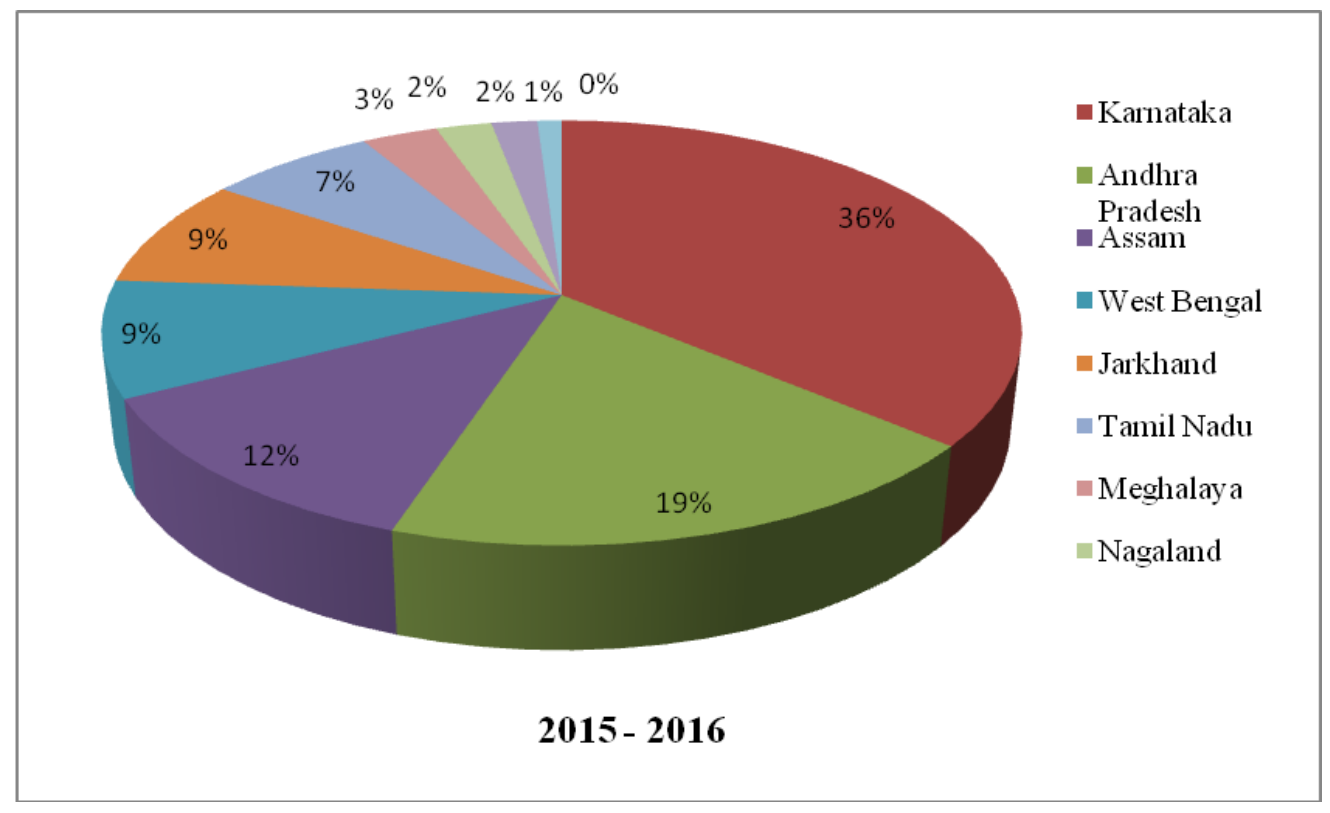

Fig. 3: India's raw silk production during the period 2015-2016 
Factors Catalyse Eri-Muga Silk Production- The increasing trend in Eri and Muga silk production in the country can be attributed to divergent factors. Although farmers have been doing these two silkworm culture in almost traditional ways with little technological intervention, even the production growth curve shows annual increase. Main factors behind increased silk production in the country are different centrally sponsored farmer's friendly schemes by Central Silk Board such as SGSY, CDP, VCPP, and NERTPS ${ }^{[16]}$. During the IX plan and onward three centrally sponsored schemes (Catalytic Development Programme) had been implemented through the sericulture Department of state governments. During 2015-16, Government of India increased the state's chare in net proceeds of union tax revenue from $32 \%$ to $42 \%$. As such central government discontinue CDP as centrally sponsored scheme with effect from 2015-16. Instead a new central scheme called Integrated Scheme for Development of Silk Industry focusing on intervention in critical areas such as breed, seed, post cocoon technology and capacity building. Few components of CDP are also incorporated in this scheme. Due to effective implementation of these schemes from IX plan onwards to end of these schemes in 2015-16 had an impact on gradual increase in silk production both in Eri and Muga sector. Further, due to fast advancement of Fashion Technology, use of Eri and Muga yarn increases in diversified fabrics creating a huge market demand. As result, farmers and stakeholders are getting their legitimate prices of their produces. Furthermore, a little bite technological interventions in these two sectors of silk industry may also be credited for increased production.

Biodiversity Resources- NE region of India naturally flourish with reach diversity of flora and fauna. It's gained the credit one of the richest biodiversity hot-spot of the world ${ }^{[6]}$. Thus, there exist a wide range of Biodiversity sericulture related bio-resource both food plants and wild counterparts of Eri and Muga silkworm. In case of Eri silkworm food plant, a great variety of food plants are available in wild and cultivated conditions [17,18]. Castor i.e. Ricinus communis Linn. alone has more than 41 varieties being different from each other in more than one character. These naturally occurring castor varieties had been evaluated for Eri silkworm rearing purpose and recommended RB1 and RB3 as having highest rearing performance. Another secondary food plant of Eri silkworm e.g. Tapioca (Manihot esculenta) has eleven known varieties. Other Eri silkworm food plants are Kesseru (Heteropanax fragrans Seem), Payam (Evodia fraxnifolia), Bar-kesseru (Ailanthus excelsa), Barpat (Ailanthus grandis), Gulancha (Plumeria acutifolia), and Gamari (Gmelina arborea). Similarly Muga silkworm also feeds on a variety of food plants available in wild and cultivated conditions. Primary food plant of Muga silkworm are Som (Persea bombysina Kost.) and Soalu (Litsaea polyantha Juss) that were cultivated for Muga rearing. Within the species of Persea bombycina Kost ${ }^{[7]}$, several morpho-types are found in naturally growing conditions. Out of these, S-3 and S-6 morpho-types have been recommended as best for Muga silkworm rearing. Other food plants of Muga are Digloti (Litsaea salicifolia Hook.), Mejankari (Litsaea cubeba Lour.), Bogori (Zizyphus jujuba Mill.), Champa (Michelia champaca Linn.), Bhomloti (Symplocous grandifolia Wall.), Patigonda (Actinodaphne obovata Blume.), Gamari (Gamelina arborea Linn.), Panchapa (Magnolia sphenocarpa Roxb.), Katholua (Cyclicoda phnenitida Roxb.), Gansarai (Cinnamomum glanduliferum Meissu.), and Bojramoni (Xanthoxylum rhesta DC).

Further, a lot of plant species are available in this region that produces natural dyes of attractive colour. These are Lettaccu, Termarid, Onion, Carrot, Tomato, Jack tree etc. For colouring the Eri yarn, extracts of roots, barks, leaves, flowers, fruits are used in single or in combination more than one plant species ${ }^{[10]}$. There are at least three species of Eri have been in record of which Samia ricini Donovan. It is domesticated while S. cynthea and S. canningiis wild Eri silkworm found in the forest of Assam and Meghalaya ${ }^{[11,19]}$. Unlike, Antharaea assamensis Helfer has no reported species within the genus. However, some scientists reported wild counterparts of Antharaea assamensis Helfer as Wild Muga or Wild Races. But still, these are not established as genetically different from domesticated Antharaea assamensis Helfer but some other serigenus insect that produced Muga like cocoon, such as Attacus atlas, Cricula trifenestrata etc ${ }^{[20,21]}$.

Product Diversification- Besides being used as fabrics, sericulture can be diversified for more economic benefit. Diversification of fabrics according to human use is very much beneficial for economic growth of these two industries ${ }^{[5,22]}$. Previously, only Eri swale of Eri silk and 
'Mekhela-Sador' of Muga silk had been used by people, but at present Eri and Muga fabrics have been used for different ways as these two silks can be blended with other types of fabrics producing materials [10,11,23]. Further, both Eri and Muga culture can practice for some other important economical practices such as intercropping of food plant garden for increasing productivity of land used, wastes as organic farming for other crops, Eri pupa as food items, Pupa as poultry food, Pupa in piece culture, Pupa in cosmetics etc ${ }^{\text {[24] }}$.

Research Potentiality- Rich bio-diversity of serigenus insect and their food plants are great source for research activities to develop silk industry, particularly through breeding and genetic engineering research. In Eri silkworm food plants, there is considerable genetical diversity within the genus, even species of Ricinus communis ${ }^{[7,8,25]}$. There are about 41 natural varieties of Ricinus communis so far reported besides of species of Ailanthus. Similarly, Muga food plants also have diversity within the species of Persea bombysina and genus Litsaea. Persea bombysina has several morpho-types providing scope for breeding research to develop breed for various beneficial characters. Within Litsaea genus there exist several food plant species of Muga silkworm [10].

Samia ricini has two wild counterparts e.g. Samia cyanthea and Samia canningi. So, there is a possibility to take breeding research with purpose to develop new high yielding breed of Eri silkworm. Moreover, within the Samia ricini, there exist six different strains and ten different eco-races. One improved Eri silkworm hybrid so called C2 breed had been developed through breeding research. In case of $A$. assamensis, there is no genetically variant wild counterpart so far reported. But some other serigenus species similar to $A$. assamensis has been reported such as Attacus atlas, Cricula trifenestrata etc ${ }^{[20]}$. This diversity in species of serigenus insects opens space for genetic engineering research for improvement of Muga silk industry ${ }^{[26]}$.

Sericulture along with Agriculture- Sericulture is purely an environmentally friendly natural cultural practice. The present trend of diversification of Sericulture opens new horizon interlinking with other livelihood practices like agriculture, pisciculture and poultry ${ }^{[27,28]}$. Thus, Eri culture and Muga culture may help in organic farming of various agricultural crops as wastes may be used as organic manure. In the similar line, the pupa of Eri and Muga may also be used as food in piece culture as well as in poultry ${ }^{[29,30]}$. Again in food plant plantation land of Eri and Muga silkworm can be utilized for intercropping to increase the productivity of land used for additional income of farmer ${ }^{[6,31]}$.

\section{CONCLUSIONS}

Muga culture and Eri Culture has scopes to bring a change in the rural economy as sustainable technological intervention can increase production in these two sectors many folds. These are rural base cultural activities and increase production that will open the door for more manpower engagement at various stakes. Moreover, diversification of use and growing market demand due to the advancement of Fashion technologies will also help Muga and Eri Stakeholders for more economic benefits. Research activities on rich Seri Biodiversity will support to improve these two sectors of sericulture. So, appropriate research planning is utmost necessary at the present time for practical utility exploiting these rich biodiversity resources.

\section{ACKNOWLEDGMENTS}

Pleasure to take the privilege of opportunity to acknowledge SEED division (Science for Equity Empowerment and Development), Department of Science and Technology, Government of India, New Delhi and, Central Muga Eri Research and Training Institute, Central Silk Board, Lahdoigarh for giving financial and logistic support to complete this work.

\section{CONTRIBUTION OF AUTHORS}

Research concept- Dr. Himangshu Barman

Research design- Dr. Himangshu Barman

Supervision- S.A.S. Rahman

Materials- Meghasree Baishya

Data collection- Meghasree Baishya

Data analysis and interpretation- Dr. Himangshu Barman, Meghasree Baishya

Literature research- Dr. Himangshu Barman, Meghasree Baishya

Writing articles- Dr. Himangshu Barman, Meghasree Baishya

Critical review- Dr. Himangshu Barman

Article editing- Dr. Himangshu Barman

Final approval- S.A.S. Rahman 


\section{REFERENCES}

[1] Shastri BN. The Kalika Puran, Venkateshvara Press, 1907; 268-303.

[2] Choudhury PC. The history of civilization of the people of Assam to the $12^{\text {th }}$ century A.D. Gauhati, dept. of historical and antiquarian studies in Assam, 1959; 14: 363.

[3] Shodhganga. History, distribution and present status of muga culture, Chap. 2, 2016; 16-29.

[4] Roy K, Bhattacharya C. A histo-geographical account of silk route: the caravan of trade, culture and political hegemony. Int. J. Innov. Res. Adv. Stud., 2017; 4(3): 269-72.

[5] Vasu NN. The social history of Kamrupa. 2008; 117-296.

[6] Ahmed SA, Rajan RK. Exploration of Vanya Silk Biodiversity in North Eastern Region of India: Sustainable Livelihood and Poverty Alleviation. International Conference on Management, Economics and Social Sciences (ICMESS), Bangkok, 2011; 485-89.

[7] Thangavelu K, Bhagawati AK, Chakraborty AK. Studies on Some Wild Sericigenous Insects of NorthEastern India. Serico., 1987; 27: 91-98.

[8] Bhattacharya A, Singh BK, Das PK. Biodiversity of Wild Silk moths in Assam (North East India). Ann. Forst., 2004; 12: 208-16.

[9] Kakati LN, Chutia BC. Diversity and Ecology of Sericigenous Insects in Nagaland, India. Trop. Eco., 2009; 50(1): 137-46.

[10]Choudhury SN. Sericulture in Assam Past, Present and Future. Seminar on Sericulture and Handloom Industries. Directorate of Sericulture, Government of Assam, 1984: 3.

[11]Bhattacharya A, Teotia RS. Conservation strategies of wild silk moths in the North-Eastern Region of India. Int. J. Wild Silkmoth \& Silk, 2000; 5: 311-13.

[12]Bhattacharya A, Saikia SK, Goswami D. Scientific Inference to the Traditional Muga Rearing. Indian Silk, 1993; 32 (8): 35-41.

[13]FAO. Women, Agriculture and Rural Development: A Synthesis Report of the Near East Region. Sustainable Development Department (SD), 1995.

[14]Das NK. Production mechaniques of Muga and Eri of Assam-A Case Study. Int. J. Multidiscip. Res. Mod. Educ., 2016: 426-33.
[15]M/O Statistics \& Programme Implementation. Raw Eri Silk production in 4 NE States of India during the period 2010-2011 to 2015-2016.

[16]Central silk Board, Ministry of Textile, Govt. of India; Functioning of Central Silk Board \& Note on Sericulture, 2018: 6-7.

[17]Chinnaswamy KP. Sericulture Biodiversity in India. Participatory Biodiversity Conservation in South Asia Region. Fonarem, Kathmandu, Nepal, 2001: 54-61.

[18] Kalita T, Dutta K. Biodiversity of Sericigenous Insects in Assam and their role in Employment Generation. J. Entomol. Zool. Stud., 2014; 2(5): 119-25.

[19]Gogoi B, Goswami BC. Silkworm Biodiversity of Assam: Its Exploration and Development. Int. J. Interdiscip. Res. Sci. Soc. Cult., 2016; 2(1): 400-07.

[20]Sahu AK. Biodiversity of Muga Silkworm Antheraea assamensis Helfer. Present status and constrains of muga silkworm host plant germplasm conservation. Proceeding of the workshop on strategies for maintenance of non-mulberry silkworm and host plant germplasm held at Central Muga Eri Research \& Training Institute, Lahdoigarh, Jorhat, Assam, India, 2005: 77-87.

[21]Dhyani SK, Chauhan DS, Kumar D, Kushwaha RV, Lepcha ST. Sericulture-based agro forestry systems for hilly areas of north-east India. Agfort. Sy., 1996; 34: 247-58.

[22]Chakravarty R, Dutta P, Ghose J. Sericulture and traditional craft of silk weaving in Assam. In. Jr. of Tradi. Knowledge, 2010; 9(2): 378-85.

[23]Gogoi S. Assam Silk. Seri. Res. Revi. Jr. Agrl. Allied Sci., 2016: 50-54.

[24]Sarmah MC, Rahman SAS, Barah A. Traditional practices and terminologies in Muga and Eri culture. In. Jr. Trad. Knowledge, 2010; 9(3): 448-52.

[25]Wani MY, Ganie NA, Rather RA, Rani S, Bhat ZA. Seri biodiversity: An important approach for improving quality of life. Jr. Ent. Zoo. Sty., 2018; 6(1): 100-05.

[26]Borah MB, Borgohain A. State and Muga silk industries in independent Assam. Int. J. Soc. Sci. Economic res., 2018; 3(2): 495-504.

[27]Kakoti RK. Sericulture as well as eri culture as a source of employment and income. Int. J. Comput. Appl. Eng. Sci., 2012; 11(S): 370-72.

[28]Baruah S. Assam Silk Market: Problems and Probable Solutions. Int. J. Innov. Res. Sci. Eng. Technol., 2016; 5(7): 12338-42. 
[29]Heuze V, Tran G, Giger RS, Lebas F. Silkworm pupae meal. FEEDIPEDIA, 2017: 10-31.

[30]Jintasataporn O. Production performance of broiler chickens fed with silkworm pupa (Bombyx mori). J. Agric. Sci. Technol. A., 2012; 2(4): 505-10.
[31]Gogoi DK, Singh R, Dutta P, Sonowal P, Singha BB. Cultivation practices in perennial eri silkworm host plant Kesseru in eri culture. Kri. Sewa., 2013: 275. 